\title{
Neonatal Aspiration of Amniotic Fluid
}

National Cancer Institute

\section{Source}

National Cancer Institute. Neonatal Aspiration of Amniotic Fluid. NCI Thesaurus. Code C101028.

Inhalation of fluid from the amniotic sac into the lungs by the neonate. 